\title{
Right atrium and superior vena cava pressure measurements in a novel animal model to study one and a half ventricle repair as compared to Fontan type procedure
}

\author{
Anil Bhattarai ${ }^{1}$, Arben Dedja ${ }^{1}$, Vladimiro L. Vida ${ }^{1}$, Francesco Cavallin ${ }^{2}$, Massimo A. Padalino ${ }^{1}$, Gaeta- \\ no Thiene ${ }^{3}$, Giovanni Stellin ${ }^{1}$ \\ ${ }^{1}$ Pediatric and Congenital Cardiac Surgery Unit, Department of Cardiac, Thoracic and Vascular Sciences, \\ University of Padua, Padua, Italy ${ }^{2}$ Indipendent Statistician ${ }^{3}$ Cardiovascular Pathology, Department of Cardi- \\ ac, Thoracic and Vascular Sciences, University of Padua, Padua, Italy
}

\section{Correspondence \\ Dr Anil Bhattarai \\ Tribhuvan University \\ Manmohan Cardiothoracic \\ Vascular and Transplant center, \\ Kathmandu}

Email: anbh10000@yahoo.com

DOI: http://dx.doi.org/10.3126/ jcmsn.v12i4.16412

Article received: $20^{\text {th }}$ Sept 2016 Article accepted: $26^{\text {th }}$ Dec 2016

\section{ABSTRACT}

Background \& Objectives: To evaluate the advantages of the one and a half ventricle repair on maintaining a low pressure in the inferior vena cava district. Also evaluate the competition of flows at the superior vena cava - right pulmonary artery anastomosis site, in order to understand the hemodynamic interaction of a pulsatile flow in combination to a laminar one. Materials \& Methods: Adult rabbits $(\mathrm{n}=30)$ in terminal anaesthesia with a follow up of $8 \mathrm{~h}$ were used, randomly distributed in three experimental groups: Group 1: animals with an anastomosis between superior vena cava and right pulmonary artery, as a model of one and one half ventricle repair; Group 2: animals with the cavopulmonary anastomosis followed by clamping of the right pulmonary artery proximal to the anastomosis; and Group 3: sham animals. Pressures of superior vena cava and pulmonary arteries were afterwards measured, in a resting condition as well as after induced pharmacological stress test. Results: In Group 1, superior vena cava pressure was significantly higher, while venous pressure in the inferior vena cava - right atrium district was constant or lower in comparison with the other groups. After stress test, the pressure in the superior vena cava and the heart rate both increased further, but the right ventricular, right atrial and pulmonary artery pressures remained similar to the values in a resting condition. This proved that the inferior vena cava return was well-preserved, and no venous hypertension was present in the inferior vena cava district even after stress test (good exercise tolerance). Conclusion: One and one half ventricle repair can be considered a good surgical strategy for maintaining a low pressure in the inferior vena cava district with potential for right ventricle growth, restoring the more physiological circulation in borderline or failing right ventricle conditions. The experiment presented a positive finding in favour of one and one half ventricle repair, as compared to Fontan type procedure.

Key words: Congenital heart disease; 1.5 ventricle repair; surgery; rabbit

Citation: Bhattarai A, Dedja A, Vida VL, Cavallin F, Padalino MA, Thiene G, Stellin G. Right atrium and superior vena cava pressure measurements in a novel animal model to study one and a half ventricle repair as compared to Fontan type procedure. JCMS Nepal. 2016;12(4):143-9.

\section{INTRODUCTION}

Right ventricle (RV) hypoplasia is a congenital heart defect associated to a wide spectrum of complex cardiac malformations. These anomalies are characterized by a normal functioning left ventricle, and a hypoplasia of the RV, which is not able to manage the whole cardiac output, resulting in a various degree of inadequate blood flow to the lungs and signs of right ventricular failure. ${ }^{1}$ Following the pioneer work of Carlo Carlon in an animal model in the early fifties, ${ }^{2}$ Glenn $^{3}$ demonstrated the clinical use of a superior vena 
cava (SVC)-right pulmonary artery (PA) shunt in 1958. Since then, a number of different cavopulmonary shunts for palliation of the cyanotic heart diseases have been reported. In 1971 Fontan described the right atrial (RA) to PA anastomosis as a surgical treatment for tricuspid atresia. ${ }^{4}$ Many modifications of this technique followed, expanding the Fontan concept to all malformations characterised by a functional single ventricle and modifying the initial Fontan concept to achieve a better hemodynamic performance. Today we know that patients after cavopulmonary shunt may suffer from important complications, such as pleural effusion, thromboembolism, arrhythmia, proteinlosing enteropathy, plastic bronchitis, pancreatitis, liver cirrhosis, nephropathy with microalbuminuria, neurocognitive deficits, arteriovenous malformations and collaterals, reduced heart rate variability, and endothelial dysfunction. ${ }^{5,6}$ Many of these complications are related to hypertension in the inferior vena cava (IVC).

As a continuation of the modifications in cavopulmonary shunts, in 1989 Billingsly et $\mathrm{al}^{7}$ published the so called "one and one half ventricular repair" (1.5 VR), which intended to achieve a more physiological correction by separating the pulmonary circulation from the systemic one, maintaining a pulsatile blood flow in the pulmonary arteries in selected patients with hypoplasic, failing or borderline RV for biventricular correction. In this repair, blood from SVC is diverted directly into the PA as a bidirectional cavopulmonary shunt, while the IVC blood is propelled by the hypoplasic RV into the PA. So, the main goal of the $1.5 \mathrm{VR}$ remains maintaining a lower pressure in the IVC district, minimizing the complications related with IVC hypertension after a Fontan procedure. ${ }^{8}$

\section{MATERIALS AND METHODS}

Animals and experimental design: Thirty New Zealand rabbits, five to six months old, weighting 4.4 to $5.5 \mathrm{~kg}$ were used. All animals were housed, handled, and treated in accordance with the guidelines and regulations set forth by the local Ethic Committee and according to the Italian Law on the use of experimental animals (DL n. 16/92, art. 5). Animals were randomly divided into three experimental groups: Group $1(\mathrm{n}=10)$ : animals with anastomosis between SVC cava and right PA (the 1.5 VR group); Group $2(\mathrm{n}=10)$ : animals with anastomosis between SVC cava and right PA, which is followed by clamping of the right PA proximal to the cavopulmonary anastomosis; and Group $3(n=10)$ : sham controls.

Anaesthesia and surgical technique: The operative procedures were carried out under general anaesthesia. Pre-anaesthesia was induced with tramadol hydrochloride (Contramal ${ }^{\circledR}$, Formenti Srl Verona, Italy) $4 \mathrm{mg} / \mathrm{kg}$ and, subsequently, tiletamine -zolazepam (Zoletil®, Virbac Srl, Milan, Italy) $15 \mathrm{mg} / \mathrm{kg}$ i.m. with xylazine (Rompun ${ }^{\circledR}$, Bayer $A G$, Leverkusen, Germany) $5 \mathrm{mg} / \mathrm{kg}$ i.m. (put in the same syringe). The auricular vein was incannulated with a $24 \mathrm{G}$ cannula and $0.9 \% \mathrm{NaCl}$ solution administered at a velocity of $5 \mathrm{~mL} / \mathrm{kg} / \mathrm{h}$. Vital signs were measures as in a standard operating room. To measure the blood pressure during and after performing the procedure, artery in the left auricle was cannulated with a $16 \mathrm{G}$ cannula. Saturation rate, heart rate, ECG monitoring was also achieved with the use of standard operating room monitor (Siemens SC 9000). Intubation was performed with direct tracheostomy incision, using a paediatric cuffed endotracheal tube of 3.5 Fr. After intubation, the endotracheal tube was fixed with open-weave bandage, tied around the connector and then connected with a OLMEDA Excel 210 SE mechanical ventilator. General anaesthesia was maintained with Oxygen $2 \mathrm{~L} / \mathrm{min}$ and sevofluorane (Sevorane ${ }^{\circledR}$, Abbott Spa, Latina, Italy) at 3\%. The ventilating values were: tidal volume $15 \mathrm{~mL} / \mathrm{kg}$, respiratory rate $26 \mathrm{rpm}, \mathrm{FiO} 2$ at $100 \%$, PEEP at 3 $\mathrm{cm} \mathrm{H} 2 \mathrm{O}$, PEAK between 10 and $15 \mathrm{~cm} \mathrm{H} 2 \mathrm{O} .{ }^{9}$ Two technicians, one operating nurse and three surgeons were involved in this procedure. The operation was performed through a left lateral thoracotomy in the third intercostal space. The animal was heparinised with the dose of $100 \mathrm{IU} / \mathrm{kg}$ of heparin. The cavopulmonary anastomosis was performed without cardiopulmonary bypass (Figure 1). For animals in Group 1 anastomosis was made in an end to side fashion between the right SVC and the right PA, as schematically shown in Figure 2. Two curve Satinsky clamps were used. Prolene 6-0 suture served for the anastomosis. In experimental Group 2, immediately after the cavopulmonary anastomosis, a vascular clamp was placed distal to the anastomosis, close to the pulmonary trunk, as schematically shown in Figure 3. Rabbits were monitored during surgery with standard monitoring techniques. At 8 hours from the beginning of surgery, as stated by the Ethical Committee, 
animals were euthanized in the operating room with a dose of $0.3 \mathrm{ml} / \mathrm{kg}$ of intrapulmonary Embutramide/Mebezonium Iodide/Tetracaine (Tanax $\left.{ }^{\circledR}\right)$ (Intervet Italia S.r.l., Milan, Italy).

Experimental measurements: Measures of blood pressure from the SVC, RA, RV and PA at rest and after induced stress test were detected with at least five measurements with a $5 \mathrm{~min}$ interval in between. Pharmacological stress test was performed by giving intravenously adrenaline bolus of 0.02 $\mathrm{mcg} / \mathrm{kg}$. A median value for each pressure was recorded.

Statistical analysis: Continuous data were expressed as median and interquartile range (IQR). Due to the small sample size, comparisons among independent samples and between paired samples were performed using the permutation approach for hypothesis testing by Non Parametric Combination (NPC). ${ }^{10}$ Statistical analysis was performed using NPC 2.0 software (http://static.gest.unipd.it/ $\sim$ salmaso/NPC TEST.htm) and R 2.12 language. ${ }^{11}$
P-value less than 0.05 was considered significant.

\section{RESULTS}

All animals tolerated well the experimental procedures, that were carried out without complications.

Numerical values of the measurements conducted throughout the experiment are shown in Table 1 (resting condition) and Table 2 (after induced stress test).

RA pressure (which reflects the pressure in IVC). At resting condition, RA pressure was significantly lower in Group 1, in comparison with controls ( $\mathrm{p}$ value $=0.01)$. After stress test, RA pressure was also found significantly lower in Group 1 ( $\mathrm{p}$ value $=$ 0.003 ), as shown in Figure $4 \mathrm{~A}$. This proves a decreasing of the pressure in the IVC district.

Hemodynamic changes in SVC. Pressures in SVC resulted much higher in Group 1, in comparison with Groups 2 and 3. This was found at resting condition ( $\mathrm{p}$ value $=0.0001$ ), as well as after stress test $(\mathrm{p}$ value $=0.0001)$, as shown in Figure 4 B.

Table 1. Resting condition. Numerical values: median (range)

\begin{tabular}{|ccccc} 
& Group 1(1.5 VR) & Group 2(clamping) & Group 3 (sham) & p-value \\
\hline RA & $7.0(6.0-7.0)$ & $8.0(7.0-8.0)$ & $7.5(7.0-8.0)$ & $\mathbf{0 . 0 1 *}$ \\
\hline SVC & $22.0(20.5-23.0)$ & $6.0(6.0(5.0-6.0)$ & $4.0(3.3-5.0)$ & $\mathbf{0 . 0 0 0 1 *}$ \\
\hline RV s & $14.5(13.0-15.0)$ & $18.0(17.3-18.0)$ & $15.5(14.3-17.8)$ & $\mathbf{0 . 0 0 0 6 *}$ \\
RV d & $4.0(4.0-4.8)$ & $5.0(5.0-5.8)$ & $5.0(4.3-5.8)$ & 0.08 \\
\hline PA s & $15.0(14.0-16.0)$ & $16.5(16.0-17.0)$ & $15.5(14.3-17.0)$ & 0.19 \\
\hline PA d & $4.0(4.0-5.0)$ & $4.0(4.0-4.8)$ & $5.0(4.3-6.8)$ & $\mathbf{0 . 0 1 *}$ \\
\hline
\end{tabular}

PA: pulmonary artery; RA: right atrium; RV: right ventricle; SVC: superior vena cava; d: diastolic pressure; s: systolic pressure; *significantly different values of Group 1 , in comparison with the other groups.

Table 2. After pharmacologically induced stress test. Numerical values: median (range)

\begin{tabular}{|ccccc} 
& Group 1(1.5 VR) & Group 2(clamping) & Group 3 (sham) & p-value \\
\hline RA & $7.5(6.0-8.0)$ & $9.0(8.3-10.0)$ & $8.5(7.3-9.0)$ & $\mathbf{0 . 0 0 3 *}$ \\
\hline RVC & $36.0(34.0-37.5)$ & $13.0(12.0-13.8)$ & $5.0(4.0-5.8)$ & $\mathbf{0 . 0 0 0 1 *}$ \\
\hline RV d & $14.5(14.0-15.0)$ & $19.0(18.3-20.0)$ & $17.0(15.3-19.5)$ & $\mathbf{0 . 0 0 0 3 *}$ \\
PA s & $4.0(3.0-4.0)$ & $5.0(5.0-5.0)$ & $5.0(5.0-5.8)$ & $\mathbf{0 . 0 0 2 *}$ \\
\hline PA d & $4.0(15.0-16.0)$ & $18.0(16.5-20.0)$ & $16.5(15.3-18.0)$ & $\mathbf{0 . 0 3 *}$ \\
\hline
\end{tabular}

PA: pulmonary artery; RA: right atrium; RV: right ventricle; SVC: superior vena cava; d: diastolic pressure; s: systolic pressure; *significantly different values of Group 1, in comparison with the other groups. 


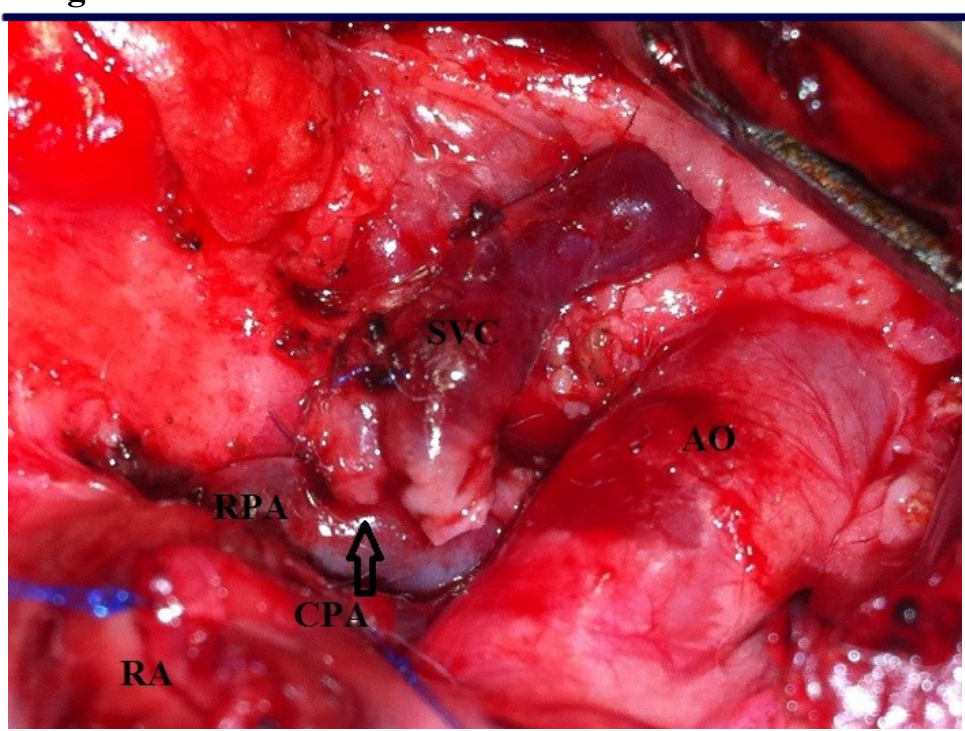

Figure 1: Intraoperative view of the cavopulmonary anastomosis in a rabbit; SVC: superior vena cava; RPA: right pulmonary artery; CPA: cavopulmonary anastomosis; $\mathrm{RA}$ : right atrium; RV: right ventricle.
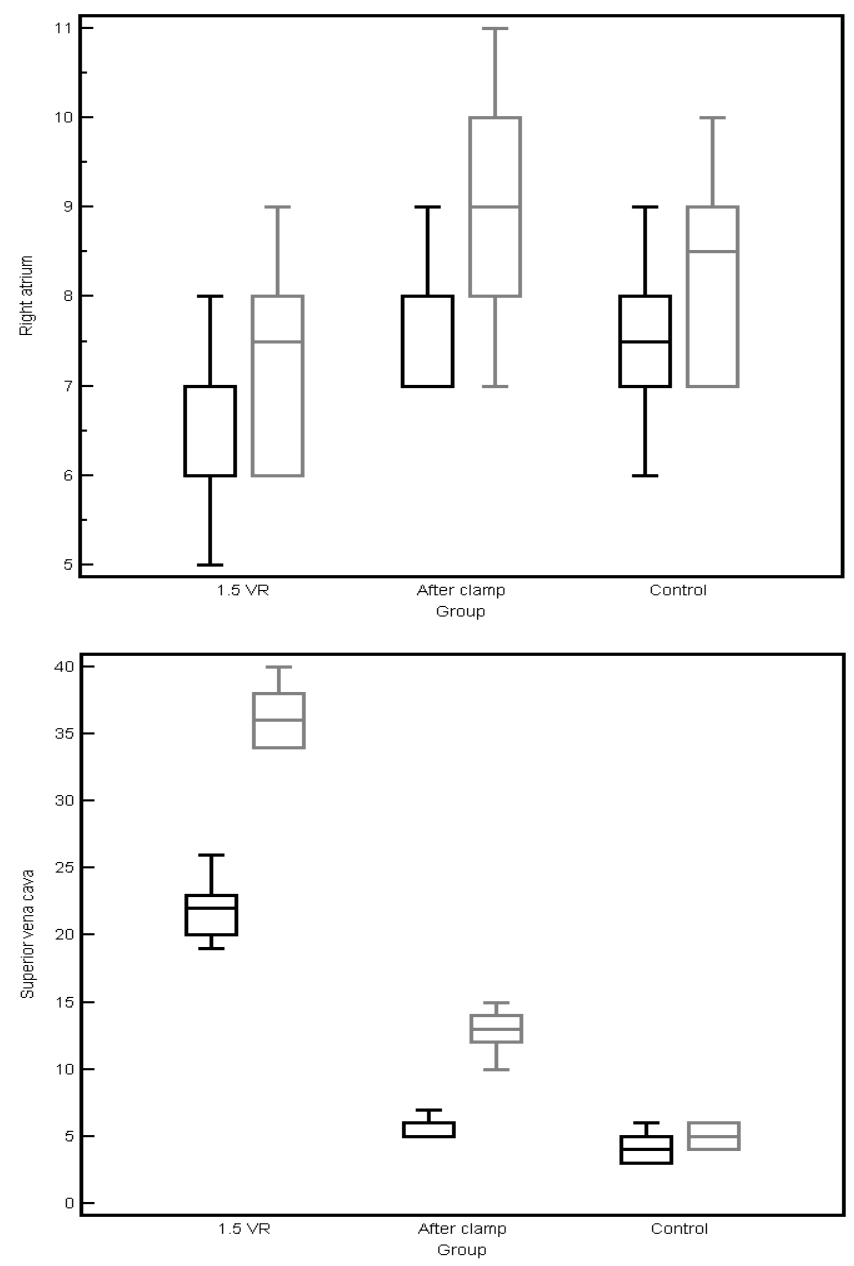

Figure: 4. Boxplot of Right Atrium (A) and Superior Vena Cava (B) in resting and stress condition.
B

Condition
Z Resting
- Stress

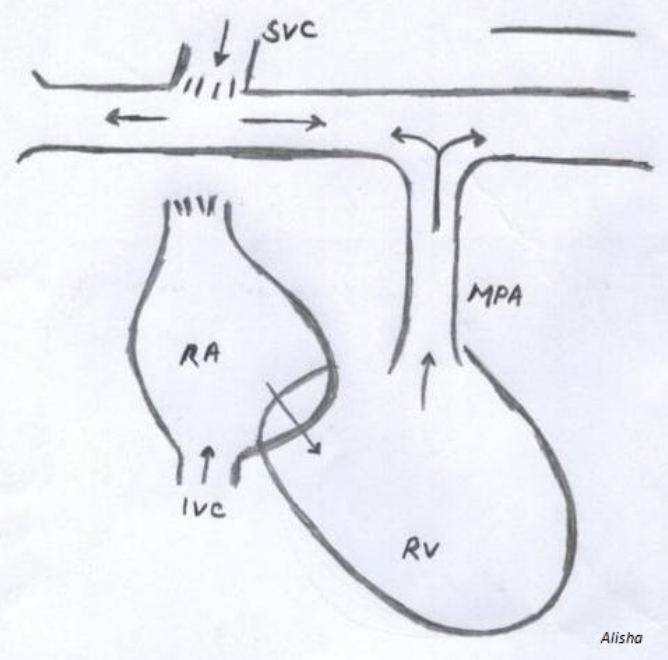

Figure 2: Diagram showing the heart after one and a half ventricle repair; SVC: superior vena cava; RA: right atrium; IVC: inferior vena cava; RV: right ventricle; MPA: main pulmonary artery; (arrow):
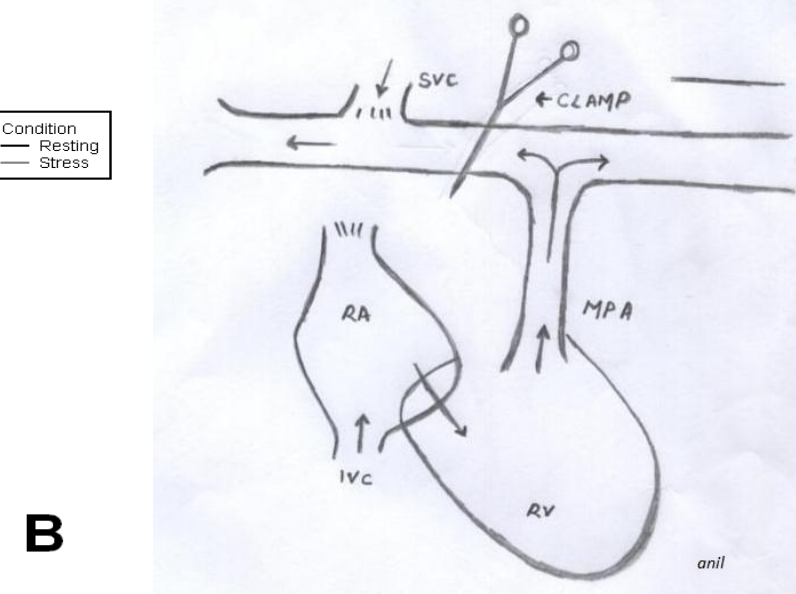

Figure 3: Diagram after placing the clamp; SVC: superior vena cava; RA: right atrium; IVC: inferior vena cava; RV: right ventricle; MPA: main pulmonary artery; clamp: vascular clamp; (arrow): direction of the blood flow. 
Although after the induced stress test the pressure in SVC increased, pressures in RV, RA and PA maintained the same values as during rest condition.

\section{DISCUSSION}

In our experimental model, we studied the hemodynamic changes after an anastomosis between SVC and right PA at the level of the anastomosis and in the RA. This procedure, applied in 10 healthy rabbits, mimicked the intervention of 1.5 ventricle repair published by Billingsly in 1989 . The data of this group of animals were compared with two control groups: sham, and a group of animals where the anastomosis was followed by a proximal cross clamping of the right PA ("mimicking" pressures of a Fontan intervention). As compared with the requirements of a marginal systemic ventricle, the $1.5 \mathrm{VR}$ for hypoplasic or failing RV, offers the considerable advantage of a variable volume load on the right while largely separating the systemic and pulmonary circulations. $^{7,}{ }^{12-21}$ The surgical management of patients with mild to moderate RV hypoplasia has improved, but the management of those with an RV which is too small to accommodate the entire cardiac output has been less satisfactory. ${ }^{7,21-23}$ The goals of surgical intervention for this group are to eliminate cyanosis by separating the pulmonary and systemic circulations while avoiding complications related to venous hypertension in IVC district. These goals are trying to be met by using different modifications of Fontan type procedures, or by establishing a RV-PA continuity using a bidirectional cavopulmonary anastomosis, in order to reduce the volume of systemic venous return that the RV must handle. ${ }^{7,22-24}$ By maintaining the RV in the atriopulmonary circulation, RV growth may continue and the pulsatile flow may enhance PA growths. ${ }^{1}$ A pulsatile pulmonary flow within pulmonary district may be advantageous if we consider that the vascular resistance to pulsatile flow is lower than to non-pulsatile flow, ${ }^{25-26}$ regional pulmonary blood flow may be more uniform ${ }^{27}$ and lymphatic drainage may improve. ${ }^{28}$ The role of non-pulsatile blood flow in the development of pulmonary arteriovenous fistulae is more controversial. ${ }^{29-33}$ Exclusion of hepatic venous return from the pulmonary circulation may be associated with the formation of such fistulae in patients following a classic Glenn-type cavopulmonary anastomosis. ${ }^{33,34}$ We hypothesize that establishing a communication between the IVC and the pulmonary arteries may be important in preventing pulmonary arteriovenous malformations. ${ }^{32-33}$ There is a potential disadvantage to this operative approach: the increased reverse flow to the SVC, but it has proved to be well tolerated by patients with Fontan procedure at midterm and long term follow-up1. Our animal study showed in real time well tolerated hemodynamic changes with increased pressure at SVC level with normal RA pressure after a SVC bidirectional PA anastomosis, even after induced stress test. That means patients after an $1.5 \mathrm{VR}$ could avoid all those complications related with venous hypertension in IVC after Fontan operation. This is a very positive finding in favour of $1.5 \mathrm{VR}$, in comparison to Fontan type procedure for patients with hypoplasic, failing or borderline RV. This proves that the IVC return is well preserved, and no hypertension is present in the IVC district even after stress test (good exercise tolerance).

Statistical analysis. The methodology used was a conditional testing procedure which works under the assumption that exchangeability of data with respect to groups is satisfied in the null hypothesis. It can be used in presence of missing values or small sample size data (thanks to its non-parametric nature) and does not require the definition of a distributional model. Pairwise comparisons after each three groups' comparison were not performed because of the small sample size A.

Limitations. They are of course some limitations to our study. Mainly, the animal model is that of healthy animals with normal sized right ventricle. Also, for ethical reasons, a follow up period of only eight hours in the operating room was possible.

\section{CONCLUSION}

We found significant increase of the SVC pressure in Group 1 (as a model of 1.5 VR). Moreover, pressure in SVC after stress test further increased, as compared to a resting condition. However, our experience of more than three decades in patients with Fontan type procedure1, proves that elevated SVC pressure is well tolerated. In addition, we found that RA pressure in Group 1 was significantly lower, which means that subjects with this type of repair is very likely to have not serious complications related with venous hypertension in IVC after Fontan type procedure, such as protein loosing enteropathy, hepatic venous congestion, plastic bronchitis, etc. Finally, the 1.5 VR seems to 
provide, even experimentally, low pressure in the IVC district, restoring the more physiological, pulsatile blood flow. The 1.5 VR is a valid option for surgical repair of hypoplasic, failing or borderline RV and a valid alternative to heart transplantation in severe RV dysfunction.

\section{Acknowledgements}

Author (A. Bhattarai) wish to inform that this project won the "The Francis Fontan Prize" in 2011. Also the preliminary results of the above study were presented at the $26^{\text {th }}$ Annual Meeting of the European Association for Cardio-Thoracic Surgery (EACTS) in Barcelona (Spain) at the Honour Guest Lecture Section, on October 2012.

\section{REFERENCES}

1. Stellin G, Vida VL, Milanesi O, Rubino M, Padalino M.A, Secchieri S, et al. Surgical treatment of complex cardiac anomalies: the "one and one half ventricle repair". Eur J of Cardio-thoracic Surg. 2002;22:1043-9. DOI: 10.1016/S10107940(02)00368-8.

2. Carlon CA, Mondini PG, De Marchi R. Surgical treatment of some cardiovascular diseases. J Int Coll Surg. 1951 Jul;16(1):111. PMID: 14850758.

3. Glenn WW. Circulatory bypass of the right side of the heart. IV shunt between superior vena cava and distal right pulmonary artery; report of clinical application. N Engl J Med. 1958;259:117-20. DOI: 10.1056/NEJM195807172590304. PMID:13566431.

4. Fontan F, Bandet E. Surgical repair of tricuspid atresia. Thorax. 1971:26:240-8. DOI: 10.1136/thx.26.3.240. PMID:5089489.

5. Jiang-Ping X, Xin-Jin L, Jun-Ming C, Shou-Jun L, YingLong L. Total cavopulmonary connection with off-pump technique. Asian Cardiovasc Thorac Ann. 2005;13:225-8. DOI: 10.1177/021849230501300307.

6. Gentles TL, Gauvreau K, Meyer JE, Fishberger SB, Burnett J, Colan SD, et al. Functional outcome after fontan operation: factors influencing late morbidity. J Thorac Cardiovasc Surg. 1997;114(3):392-403. DOI: 10.1016/S0022-5223(97)70184-3. 7. Billingsly AM, Laks H, Boyce SW, George B, Santulli T, Williams RG. Definitive repair in patients with pulmonary atresia and intact ventricular septum. J Thorac cardiovasc surg. 1989;97:746-54.

8. Ujjwal KC, Diplomate NB, Balram A, Sachin T, Shyam SK, Anita S, et al. One and one-half ventricle repair: result and concerns. Ann thorac surg. 2005;80:2293-300. DOI: 10.1016/ j.athoracsur.2005.05.052. PMID:16305892.

9. UCLA Animal Care and Use Training Manual, the Chancellor's Animal Research Committee 2000. Report of the AVMA Panel on Euthanasia. JAVMA. 2001;218(5):669-96. DOI: $10.2460 /$ javma.2001.218.669.

10. Brombin C, Midena E, Salmaso L. Robust non-parametric tests for complex-repeated measures problems in ophthalmology. Stat Methods Med Res. 2013;22(6):643-60. DOI: 10.1177/0962280211403659. PMID:21705436.

11. R Development Core Team 2010. R: A language and environment for statistical computing. $\mathrm{R}$ Foundation for Statistical Computing, Vienna, Austria. ISBN 3-900051-07-0, URL http://www.R-project.org/.

12. Teske DW, Davis T, Allen HD. Cavopulmonary anastomotic aneurysm: a complication in pulsatile pulmonary arteries. Ann Thorac Surg. 1994;57:1661-4. DOI: 10.1016/0003-4975(94)90151-1.

13. Bautista-Hernandez V, Marx GR, Bacha EA, del Nido PJ.
Aortic root translocation plus arterial switch for transposition of the great arteries with left ventricular outflow tract obstruction: intermediate-term results. J Am Coll Cardiol. 2007;49:485-90. DOI: 10.1016/j.jacc.2006.09.031. PMID: 17258095 .

14. Dearani JA, Danielson GK, Puga FJ, Mair DD, Schleck CD. Late results of the Rastelli operation for transposition of the great arteries. Semin Thorac Cardiovasc Surg Pediatr CardSurg Ann. 2001;4:3-15. DOI: 10.1053/tc.2001.24649.

15. Shio K, Osman Al-R, Mark KF, Christopher AC, John GC, Erwin O, et al. Superior vena cava to pulmonary artery anastomosis as an adjunct to biventricular repair: 38 year follow-up. Ann Thorac Surg. 2009;87:1475-83. DOI: 10.1016/ j.athoracsur.2008.12.098. PMID:19379888.

16. Alvarado O, Sreeram N, McKay R, Boyd IM. Cavopulmonary connection in repair of atrioventricular septal defect with small right ventricle. Ann Thorac Surg. 1993;55:729-36. DOI: 10.1016/0003-4975(93)90284-O

17. Albolinas ET, Julsrud PR, Danielson GK, Puga FJ, Schaff HV, McGoon DC, et al. Definitive operation for pulmonary atresia with intact ventricular septum: results in 20 patients. $\mathbf{J}$ Thorac Cardiovasc Surg. 1987;93:454-64.

18. Coles JG, Freedom RM, Lightfoot NE, Dasmahapatra HK, Williams WG, Trusler GA, et al. Long-term results in neonates with pulmonary atresia and intact ventricular septum. Ann Thorac Surg. 1989;47:213-7. DOI: 10.1016/0003-4975(89) 90271-3.

19. Iacona GM, Marianeschi SM, Condoluci C, Masetti P, Abella RF, Smedile G, et al. The role of a bidirectional cavopulmonary anastomosis in the correction and palliation of complex congenital cardiopathies. G Ital Cardiol. 1998;28 (12):1372-7. PMID:9887390.

20. Maruyama Y, Nunokawa T, Koiwa Y, Isoyama S, Ikeda K, Ino-Oka E, et al. Mechanical interaction between ventricles. Basic Res Cardiol. 1983;78:544-59. DOI: 10.1007/ BF01906465. PMID:6651741.

21. Gentles TL, Keane JF, Jonas RA, Marx GE, Mayer JE Jr. Surgical Alternatives to the Fontan Procedure Incorporating a Hypoplastic Right Ventricle. Circulation. 1994 Nov;90 (5 Pt 2):II1-6. PMID:7525110.

22. De LM, Bull C, Hopkins R, Rees P, Deanfield J, Taylor JF, et al. Decision making in the definitive repair of the heart with a small right ventricle. Circulation 1985;72:II52-60.

23. Yang JH, Jun TG, Park PW, Sung K, Kim WS, Lee YT, et al. Exclusion of the non-functioning right ventricle in children with pulmonary atresia and intact ventricular septum. Eur J Cardiothorac Surg. 2008 Feb;33(2):251-6. DOI: 10.1016/ j.ejcts.2007.11.023. PMID:18164208.

24. Gittenberger-de Groot AC, Sauer U, Bindl L, Babic R, Essed CE, Buhlmeyer K. Competition of coronary arteries and ventriculo-coronary arterial communications in pulmonary atresia with intact ventricular septum. Int $\mathbf{J}$ Cardiol. 1988;18:243-58. DOI: 10.1016/0167-5273(88)90169-6.

25. Clark CP, Kahn DR, Dufek JH, Sloan H. The effects of nonpulsatile blood flow on canine lungs. Ann Thorac Surg. 1968;6: 450-7. DOI: 10.1016/S0003-4975(10)66052-3.

26. Shepard RB, Kirklin JW. Relation of pulsatile flow to oxygen consumption and other variables during cardiopulmonary bypass. J Thorac Cardiovasc Surg. 1969;58:694-702. PMID:5348159.

27. Cloutier A, Ash JM, Smallhorn JF, Williams WG, Trusler GA, Rowe RD, et al. Abnormal distribution of pulmonary blood flow after the Glenn shunt or Fontan procedure: risk of development of arteriovenous fistulae. Circulation. 1985;72:471-9. DOI: 10.1161/01.CIR.72.3.471

PMID:4017202.

28. Parsons RJ, McMaster PD. The effect of the pulse upon the formation and flow of lymph. J Exp Med. 1983;68:353-76. DOI: $10.1084 /$ jem.68.3.353.

29. Jonas RA. The importance of pulsatile flow when systemic venous return is connected directly to the pulmonary arteries. $\mathrm{J}$ Thorac Cardiovasc Surg. 1993;105:173-5. PMID:8419699.

30. Malhotra SP, Reddy VM, Thelitz S, He YP, McMullan 
DM, Hanley FL, et al. The role of oxidative stress in the development of pulmonary arteriovenous malformations after cavopulmonary anastomosis. J Thorac Cardiovasc Surg. 2002 Sep;124(3):479-85. DOI: $\quad 10.1067 / \mathrm{mtc} .2002 .120346$. PMID:12202863.

31. Cloutier A, Ash JM, Smallhorn JF, Williams WG, Trusler GA, Rowe RD, et al. Abnormal distribution of pulmonary blood flow after the Glenn shunt or Fontan procedure: risk of development of arteriovenous fistulae. Circulation. 1985;72:471-9. DOI: 10.1161/01.CIR.72.3.471

PMID:4017202.

32. Chang RR, Alejos JC, Atkinson D, Jensen R, Drant S, Galindo A, et al. Bubble contrast echocardiography in detecting pulmonary arteriovenous shunting in children with univentricular heart after cavopulmonary anastomosis. J Am Coll Cardiol. 1999;33:2052-8. DOI: 10.1016/S0735-1097(99) 00096-0.

33. Duncan BW, Kneebone JM, Chi EY, Hraksa V, Isik FF, Rosenthal GL, et al. A detailed histological analysis of pulmonary arteriovenous malformations in children with cyanotic congenital heart disease. J Thorac Cardiovasc Surg. 1999;117:931-8. DOI: 10.1016/S0022-5223(99)70374-0.

34. Albanese SB, Carotti A, Di Donato RM, Mazzera E, Troconis CJ, Giannico S, et al. Bidirectional cavopulmonary anastomosis in patients under two years of age. J Thorac Cardiovasc Surg. 1992;104:904-9. PMID:1405688. 